\title{
The impact of a gain-sharing cost-reflective tariff on waste management cost under incentive regulation: The Italian case
}

\author{
Giacomo Di Foggia, Massimo Beccarello
}

\begin{abstract}
In many European countries, waste tariff systems are being updated to take account of the consolidation of circular economy objectives. We forecast the impact of a gain-sharing costreflective tariff on waste management sustainability. The cost-reflective tariff generates an economic surplus for society, while meeting environmental goals. Based on empirical data we developed two scenarios. The baseline scenario formalizes the current Italian tariff scheme, while the intervention scenario includes users' response to a gainsharing policy. By optimizing the tariff structure, society would benefit from a surplus that could be reached setting an asymmetric regulation based on current waste management efficiency level. Our results will potentially be a basis for directing waste management policy as per tariff design.
\end{abstract}

\section{Article information}

Preprint

Di Foggia, G., \& Beccarello, M. (2020). The impact of a gain-sharing cost-reflective tariff on waste management cost under incentive regulation: The Italian case. Journal of Environmental Management, 265(March), 110526. 


\section{Introduction}

Waste management (WM) is one of the most important municipal services (Hoornweg and Bhada-Tata, 2012). Since efficient WM is central to sustainability (Mani and Singh, 2016), its cost effectiveness is at the heart of environmental policies (Buclet and Godard, 2001) worldwide. In addition, improving WM efficiency creates jobs, incentivizes responsible consumption, and protects the natural environment (Fuss et al., 2018).

Research on cost-reflective tariffs has gained renewed academic interest because ensuring cost reflectivity when determining tariffs is important, given the international commitments to move toward a circular economy (Di Foggia and Beccarello, 2018). WM is typically funded by fees paid by citizens, institutions and businesses, subsidies from the municipality's general budget, revenue from extra services, revenues from sales of materials and energy produced from waste, and income from extended producer responsibility schemes (World Bank, 2018). Since these revenues generally need to ensure the financial stability of WM, having a cost-reflective tariff system is a condition sine qua non for effective incentive regulation and a functional WM market.

In accordance with previous literature that underlined the importance of including the users' response to policy changes (Chu and Sappington, 2012), we performed an analysis of different WM tariff systems. Namely, we compare a baseline scenario, which corresponds to the current full-cost recovery scheme, with an intervention scenario that includes the users' response to policy. In doing so, we consider users' environmental performance in terms of their effective separation of waste for collection. Positive externalities from users' responses to policies can be converted to social surplus because tariffs can be reduced.

To provide a solid foundation to investigate these issue, we gathered municipal-level data from the Italian Institute for Environmental Protection and Research (ISPRA), and the Italian National Institute of Statistics (ISTAT). This enabled us to conduct empirical analysis on a sample covering $55 \%$ of Italian municipalities. From our results, three prominent considerations emerged. First, by optimizing the tariff structure, society would benefit from a surplus that corresponds to a $6.9 \%$ decrease in costs, ceteris paribus. Second, it is necessary to design regulations asymmetrically to consider the levels of environmental performance and economic efficiency of different territories. Third, incentive regulation based on a price-cap mechanism could incidentally jeopardize the social surplus. Evidence of this risk was generated by examining the gain-sharing cost-reflective tariff under specific 
conditions. To further investigate this issue, we implemented sensitivity analysis based on three hypotheses. In hypothesis 1, no quality or business model improvements are expected. Hypothesis 2 represents an intermediate hypothesis whereby both business model optimization and quality of service factors were set at their average level. Finally, in hypothesis 3 , both factors were set to their maximum.

The remainder of this paper is organized as follows. Section 2 presents the theoretical background, which includes prominent works about WM. Section 3 introduces the research design as well as the model used to perform simulations according to the scenarios. Section 4 contains key results that are subsequently discussed in section 5 , section 6 concludes.

\section{Theoretical background}

In this paper, we define a cost-reflective tariff as one that reflects the true cost of WM, net of revenues from sales of materials and revenues from the national packaging consortium, which brings together producers and users of packaging. The scope of WM considered in this paper is municipal solid WM, that is, the collection and disposal of waste generated by households (Di Foggia and Beccarello, 2018). In this context, we argue that gain-sharing plans deserve more attention. These plans represent one of the most promising topics in environmental economics due to their impact on the circular economy (D'Onza et al., 2016; Debnath and Bose, 2014; Tsilemou and Panagiotakopoulos, 2006). They are also important for cost recovery and technology investment decisions (Goddard, 1995). For this reason, the body of research focused on WM and cost-reflectivity of tariffs has grown (Bohm et al., 2010; Gullì and Zazzi, 2011; Pérez-López et al., 2016; Sarra et al., 2017). Indeed, policies which aim to turn waste into resources can make people more aware of the necessity to separate waste and can encourage industry to introduce new disposal technologies, thus increasing recycling capacities (Nelles et al., 2016). In this respect previous literature assessed the expected costs of transferring municipalities to solid waste source separation (Lavee and Nardiya, 2013) to reduce the waste sent to landfills.

Broadly speaking, there are two prevailing funding schemes for WM: fixed fees and quantitybased fees. The first is widely used due to its handling convenience and because it ensures a constant stream of revenue generation, which is valuable given that revenue management is critical for business sustainability today (Di Foggia and Lazzarotti, 2014). The second 
method assumes that users are charged according to the quantity and quality of waste produced (Chu et al., 2019).

As inferred above, the volume of literature on cost and efficiency of WM has increased (Bohm et al., 2010; Gullì and Zazzi, 2011; Pérez-López et al., 2016; Sarra et al., 2017). In particular, the use of parametric and non-parametric methods has increased exponentially in the last few years (Simões and Marques, 2012a). For example, some studies have approximated cost functions for WM (Bohm et al., 2010), allowing for the evolution in organizational, financial, management, and technological schemes, which make cost function estimation complex. However, problems have arisen in getting cost estimates due to the limited amount of publicly available data (Tsilemou and Panagiotakopoulos, 2006). Furthermore, past literature has investigated the economic efficiency of WM companies with the aim of verifying drivers for efficiency and concluded that drivers differ for different types of waste (UNEP, 2012). Some evidence about economies of scale has also emerged on the basis of the population of the municipalities and it seems that private WM companies are no more economical than public WM services (Bel and Fageda, 2010). Another study analyzed cost functions and has proposed an approach to select different WM strategies according to the technology of waste recovery and the utility functional specification (Swart and Groot, 2015).

Economic efficiency also depends on the prevailing regulation, given that effective regulation might facilitate business performance by contributing to the creation of market opportunities (Kitching et al., 2015). Nevertheless, implementing new regulations can be expensive (Di Foggia, 2018) even if can resolve allocative distortions (Guerriero, 2013). Therefore, the challenge is to find efficient regulation to resolve concerns and stimulate investment and/or to overcome information asymmetries (Cooremans, 2011; van Beukering et al., 2014).

According to the theory of economic regulation, public service providers should operate with the same level of economic efficiency as private companies in competitive markets. The regulation of revenues that the company is authorized to earn is probably the most common approach (Pérez-Arriaga, 2014). Researchers argue that, in the face of the undeniable improvements in the quality of service resulting from regulation, additional improvements should be made in terms of economic regulation research and implementation (Simões and Marques, 2012b). Indeed, robust economic regulation in WM is needed, as the sector can be 
subject to inefficient conditions due to market failures and lack of incentives (Marques et al., 2018). To this end, previous literature has clarified concepts such as taxes and charges, tariffs, environmental tax, environmental charge, subsidies, markets for environmental goods, and voluntary agreements (Pirard and Lapeyre, 2014). Cost-reflective tariffs promote economic efficiency, that is, society aims to minimize production costs while still ensuring demand is met (Jargstorf et al., 2015). Therefore, we argue that cost-reflective tariffs with good behavior incentive parameters induce positive user responses and thus, lead to economic and environmental efficiency. This holds even if economic efficiency is not the only criterion for designing tariffs (Brown et al., 2015). Users are supposed to react to the tariff by maximizing their utility, corresponding to savings in tariffs. Thus, potential societal benefits can be created in terms of savings on waste tariffs.

Policy makers responsible for WM apply different regulations and revenue systems to fund the service. Often, these systems are designed to encourage separate collection of different waste materials and recycling. Also, previous literature predicted where potential for economically efficient recycling is highest to provide policy-makers with information to help direct their efforts to promote recycling (Lavee and Khatib, 2010). Widely used schemes rely on fees based on the weight or volume of the different types of waste as an economic incentive for people and firms to reduce waste production (Morlok et al., 2017). As noted above, there is a range of options for funding the service, including a usage-pricing scheme for WM (Elia et al., 2015). In this case, users are charged according to how much waste they produce. It is often argued that this is a prominent method to directly relate user charges to contributions to environmental sustainability (Chamizo-González et al., 2018). Although the main purpose of usage-pricing schemes is to steer economic, social, and environmental sustainability of waste flows, such schemes increase the complexity of the WM service (Elia et al., 2015). Indeed, the establishment and operation of pay-charging systems like these require noteworthy economic and technical resource inputs (Morlok et al., 2017). That said, data published by the European Environmental Agency show a correlation between the implementation of these mechanisms and recycling rates. For example, European countries with recycling rates above $45 \%$ employ a similar system, while most countries with recycling rates below 20\% do not use them (EEA, 2016). Finally, an effective financial scheme is essential for supporting investments in compliance with the circular economy concept (Tisserant et al., 2017). This concept is gaining momentum, with the aim of extending the 
useful life of materials, increasing the share of goods that are recycled, promoting green technologies and businesses (Kirchherr et al., 2017), and generally lowering environmental impacts and resource use (Tisserant et al., 2017).

\section{Research design}

WM financing schemes must incentivize users' and businesses' responses (Lakhan, 2016). Thus, tariffs must be able to improve social well-being by distributing the benefits of efficiency across society. We approached this topic by conducting empirical analysis to model the WM costs according to alternative scenarios. Specifically, we modeled a baseline scenario, which depicts the prevailing Italian WM financing mechanism, and an intervention scenario, which analyses users' response to policy changes. Social surplus is defined as the shared revenues from sales of materials and energy produced from waste.

Figure 1: Research design flow chart

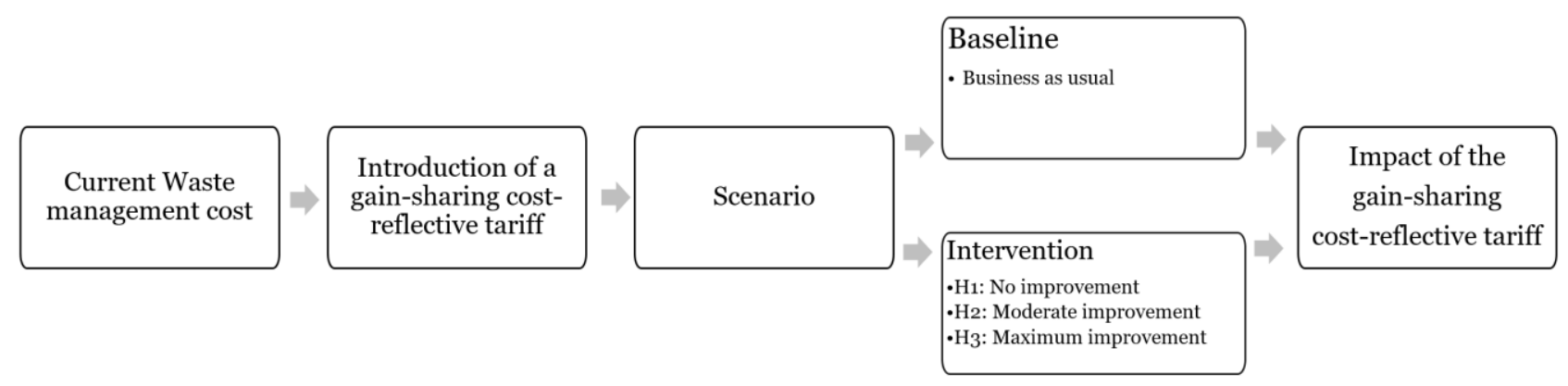

Source: own elaboration

\subsection{Population and variables}

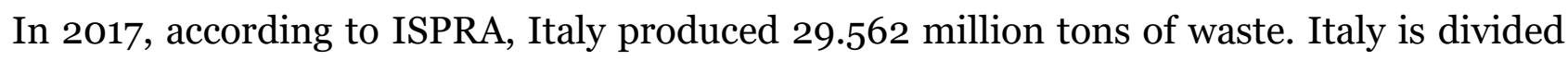
into twenty regions. These regions constituted the territorial unit variable used to aggregate data and perform the analyses and simulations. The regions are quite heterogeneous in terms of their population and the performance of their WM systems as table 1 shows.

\begin{tabular}{lccccc}
\hline Table 1: Waste production and cost in Italian regions \\
$\begin{array}{l}\text { Territorial unit } \\
\text { Regions }\end{array}$ & $\begin{array}{c}\text { Population } \\
\text { (millions) }\end{array}$ & $\begin{array}{c}\text { Waste production } \\
\text { ton (millions) }\end{array}$ & $\begin{array}{c}\text { Waste production } \\
\mathrm{kg} \text { per capita }\end{array}$ & $\begin{array}{c}\text { Separate Collection } \\
\text { Percent }\end{array}$ & $\begin{array}{c}\text { Cost per capita } \\
\text { EUR }\end{array}$ \\
\hline Abruzzo & 1.315 & 0.597 & 453.992 & 0.560 & 182.9725 \\
Aosta Valley & 0.126 & 0.057 & 452.381 & 0.677 & 179.5434 \\
Basilicata & 0.567 & 0.198 & 349.206 & 0.442 & 172.0737 \\
Calabria & 1.957 & 0.775 & 396.014 & 0.399 & 163.9445 \\
Campania & 5.827 & 2.561 & 439.506 & 0.528 & 232.9084
\end{tabular}




\begin{tabular}{lccccc} 
Emilia R & 4.453 & 2.860 & 642.264 & 0.638 & 172.8158 \\
Friuli V G & 1.216 & 0.589 & 484.375 & 0.655 & 129.5696 \\
Lazio & 5.897 & 2.967 & 503.137 & 0.456 & 223.1871 \\
Liguria & 1.557 & 0.832 & 534.361 & 0.488 & 238.3094 \\
Lombardy & 10.02 & 4.678 & 467.800 & 0.696 & 145.910 \\
Marche & 1.532 & 0.817 & 533.290 & 0.632 & 152.5113 \\
Molise & 0.308 & 0.117 & 379.870 & 0.309 & 141.0659 \\
Piedmont & 4.376 & 2.066 & 472.121 & 0.593 & 161.934 \\
Apulia & 4.048 & 1.876 & 463.439 & 0.404 & 194.5866 \\
Sardinia & 1.648 & 0.723 & 438.714 & 0.631 & 214.5442 \\
Sicily & 5.027 & 2.300 & 457.529 & 0.217 & 172.4428 \\
Tuscany & 3.737 & 2.244 & 600.482 & 0.539 & 215.4504 \\
Trentino A.A. & 1.068 & 0.519 & 485.955 & 0.716 & 142.3846 \\
Umbria & 0.885 & 0.451 & 509.605 & 0.617 & 195.4297 \\
Veneto & 4.905 & 2.335 & 476.0449 & 0.736 & 133.6187 \\
ITALY & 60.449 & 29.562 & 477.0043 & 0.54665 & 178.2601 \\
\hline Source & & & & & \\
\hline
\end{tabular}

Source: own elaboration based on ISPRA data

In order to provide a solid foundation for the study, detailed information on WM cost structure was gathered by merging official databases. Specifically, data was extrapolated from a local finance databank managed by the Department for Internal and Territorial Affairs. In cases where information was not available for the entire population, for example the cost data of the individual components were only available in $82.93 \%$ of municipalities, data were estimated by means of statistical inference. This was done using provincial data which, after statistical inference, were then interpolated to municipalities. This allowed us to overcome possible drawbacks related to missing values. Overall, our goal was to simulate the WM financing mechanism using a bottom-up approach. This was necessary in order to capture local factors that impact financial requirements for the service and in turn, the fees charged to users. Table 2 contains the list of variables used in this paper.

\begin{tabular}{llrrrr}
\hline Table 2 : Variables & \multicolumn{7}{l}{ Mean } & \multicolumn{1}{l}{ Sd } & Min & \multicolumn{1}{l}{ Max } & Unit \\
\hline Variable & Variable label & 31.943 & 34.991 & 0.141 & $113.000 €(\mathrm{~m})$ \\
\hline $\mathrm{R}_{\mathrm{me}}$ & Revenues - energy and material & 23.151 & 23.420 & 0.474 & $95.200 €(\mathrm{~m})$ \\
$\mathrm{R}_{\text {pack }}$ & Revenues - packaging consortium & 0.450 & & 30.000 & $60.000 \%$ \\
$b$ & Sharing coefficient & 21.526 & 18.939 & 0.362 & $67.200 €(\mathrm{~m})$ \\
oc & Other costs & 15.756 & 13.813 & 0.377 & $47.400 €(\mathrm{~m})$ \\
adc & Administrative costs & 5.252 & 4.604 & 0.126 & $15.800 €(\mathrm{~m})$ \\
occ & Other common costs & 105.052 & 92.112 & 2.516 & $316.200 €(\mathrm{~m})$ \\
$\mathrm{CC}$ & Common costs & 409.394 & 345.305 & 19.428 & $1.073 .200 €(\mathrm{~m})$ \\
$\mathrm{MC}$ & Management costs & 30.123 & 27.731 & 0.714 & $96.800 €(\mathrm{~m})$ \\
$\mathrm{CK}$ & Capital costs & 2.576 & 2.109 & 0.110 & $6.930 €(\mathrm{~m})$ \\
cat & Authority and Territorial ambit costs & & & &
\end{tabular}




\begin{tabular}{|c|c|c|c|c|c|c|}
\hline scc & Separate collection costs & 117.651 & 99.155 & 6.426 & 341.379 & $€(\mathrm{~m})$ \\
\hline ctc & Collection and transportation costs & 75.082 & 68.605 & $4 \cdot 352$ & 226.152 & $€(\mathrm{~m})$ \\
\hline swc & Sweeping and street washing costs & 66.084 & 61.747 & $3 \cdot 355$ & 207.000 & $€(\mathrm{~m})$ \\
\hline $\mathrm{TC}$ & Total costs & $544 \cdot 568$ & 452.102 & 22.659 & 1.459 .100 & $€(\mathrm{~m})$ \\
\hline $\operatorname{trc}$ & Treatment and recycling costs & 39.305 & 37.929 & 1.162 & 137.000 & $€(\mathrm{~m})$ \\
\hline tdc & treatment and disposal costs & 89.746 & 74.470 & 3.771 & 252.808 & $€(\mathrm{~m})$ \\
\hline biz & Business model optimization factor & 1.500 & & 0.000 & 3.000 & $\%$ \\
\hline POP & Population & 3.022 & 2.529 & 0.126 & 10.000 & $(\mathrm{~m})$ \\
\hline qlt & Quality of service factor & 1.000 & & o & 2.000 & $\%$ \\
\hline Tfa & Tangible fixed assets & 13.994 & 17.676 & 0.364 & 63.345 & $€(\mathrm{~m})$ \\
\hline$i$ & Expected inflation & 0.700 & & & & $\%$ \\
\hline $\mathrm{TF}$ & Fix costs & 222.784 & 191.385 & 6.948 & 660.100 & $€(\mathrm{~m})$ \\
\hline TV & Variable costs & 321.784 & 267.420 & $15 \cdot 711$ & 821.489 & $€(\mathrm{~m})$ \\
\hline $\mathrm{X}$ & productivity improvement in price-cap & 0.300 & & & & $\%$ \\
\hline
\end{tabular}

To generate the variables related to revenues from energy and material and from the national packaging consortium, we used the following approach. Revenues from material and energy sales were calculated as the sum of revenues from energy sales and revenues from material sales. Revenues from the packaging consortium were calculated as follows. Starting from the data published on the website of the national consortium, we extracted the total amount paid for each material: paper, glass, wood, metal (aluminum + steel), and plastic. Subsequently, we allocated this amount to municipalities using a waste production factor, that is, the percentage of production of each type of waste in the total amount of waste produced. After that, we summed up the sub-variables to obtain the final variable, which was then adjusted via a territorial factor to formalize differences in performance as per the separate collection of different types of waste.

\subsection{Model setup}

The funding required to carry out WM, that is, its total cost (TC), is arrived at by adding three components: management costs (MC), that result from the core activity of the WM, namely collection and disposal, common costs (CC) i.e. which refer to the above mentioned components, and capital costs (CK), as depicted in equation 1 below. This can be calculated by adding together total fix costs (TF) and total variable costs (TV).

$$
T C=M C+C C+C K=T F+T V
$$


Our simulations are based on two scenarios. The baseline scenario (Baseline) reflects the current policy framework in Italy, whereas the second scenario (S Intervention) depicts policy changes. Equation 2 formalizes the fix costs in both scenarios.

$$
T F=\left\{\begin{array}{lr}
s w c+a d c+g r c+o c c+C K & \text { if } S_{\text {Baseline }} \\
s w c+a d c+g r c+o c c+c a t+C K+r(t f a) & \text { if } S_{\text {Intervention }}
\end{array}\right.
$$

Similarly, equation 3 formalizes variable costs, that is, costs that correlate with the quantity of waste produced, in both scenarios. Here, the intervention scenario contains gain sharing parameters.

$$
T V=\left\{\begin{array}{lr}
\operatorname{ctc}+\mathrm{tdc}+\mathrm{scc}+\operatorname{trc} & \text { if } S_{\text {Baseline }} \\
c t c+t d c+t r c+s c c-b\left(r_{m e}\right)-r_{\text {pack }} & \text { if } S_{\text {Intervention }}
\end{array}\right.
$$

Straightforward data manipulation enables managerial costs to be computed, as per equation 4. It is worth noting that the scope of management cost is better defined in the intervention scenario as it does not contain other costs.

$$
M C=\left\{\begin{array}{cc}
s w c+c t c+t d c+s c c+t r c+o c & \text { if } S_{\text {Baseline }} \\
s w c+c t c+t d c+s c c+t r c & \text { if } S_{\text {Intervention }}
\end{array}\right.
$$

Equation 5 contains components of common costs, which are costs that are not directly allocated to different phases of service. The key difference between the two scenarios is that the second scenario contains a proxy for the cost of the regulatory body that shall be in charge of defining rules, including the incentive variables, and monitoring the application of those rules.

$$
C C=\left\{\begin{array}{lc}
a d c+g r c+o c c & \text { if } S_{\text {Baseline }} \\
a d c+g r c+o c c+c a t & \text { if } S_{\text {Intervention }}
\end{array}\right.
$$

Finally, equation 6 defines capital costs, such as amortization of trucks, equipment for sweeping, containers for collection, financial depreciation and other assets, provisions, and return on capital. The intervention scenario also includes remuneration of tangible fixed assets.

$$
C K=\left\{\begin{array}{l}
\mathrm{CK} \\
C K+\mathrm{r}(\mathrm{tfa}) \quad \text { if } S_{\text {Baseline }} \\
\text { Intervention }
\end{array}\right.
$$

The dynamics of TC, and therefore of the waste tax which is to fund the cost, is a critical aspect. As previously mentioned, revenues from tariffs (T) are updated annually using the price-cap scheme, which can be formalized in equation 7.

$$
T_{t}=T_{t-1}\left(1+\left(C P I_{t-1}-X\right)\right)
$$

Basically, $\mathrm{T}_{\mathrm{t}}$ depends on $\mathrm{T}_{\mathrm{t}-1}$ and on the relation between the consumer price index at time $\mathrm{t}_{-1}$, that is, $\mathrm{CPI}_{\mathrm{t}-1}$, and the factor $\mathrm{X}$, namely the rate of change in productivity required $\left(\mathrm{X}_{\mathrm{t}-1}\right.$ - 
$X_{t}$ ) in the period considered (Shleifer, 1985). It follows that $T_{t} \leq C P I-X$. The price-cap scheme applies to both versions of the model presented in this paper, but with a few important differences. In the baseline scenario, local authorities define the value of $\mathrm{X}$; the only constraint is that $\mathrm{X}>\mathrm{O}$ and must be able to cover capital costs. In the second scenario, parameter $\rho$ represents the maximum growth of tariffs. While this parameter takes the factor $\mathrm{X}$ into account, the value of $\mathrm{X}$ must also reflect variables that reflect the quality and scope of the service. In the baseline scenario, capital costs also included all the costs related to planned investments, with a corrective factor for the deviations that occurred between what was expected and what was achieved. According to the baseline scenario, total revenues shall reflect costs and be updated according to equation $8 . \mathrm{T}_{\mathrm{t}}$ is the total revenue, $\mathrm{MC}_{\mathrm{t}-1}$ is the total $\mathrm{WM}$ costs of the previous year, $\mathrm{CC}_{\mathrm{t}-1}$ is the common cost of the previous year, $\mathrm{it}_{\mathrm{t}}$ is the expected inflation, $\mathrm{X}_{\mathrm{t}}$ is the productivity recovery, and $\mathrm{CK}_{\mathrm{t}}$ is the capital use costs for the reference year.

$$
\mathrm{T}_{\mathrm{t}}=(\mathrm{MC}+\mathrm{CC})_{\mathrm{t}-1}\left(1+\mathrm{i}_{\mathrm{t}}-\mathrm{X}_{\mathrm{t}}\right)+\mathrm{CK}_{\mathrm{t}}
$$

As can be seen from equation 8 , the only costs subject to updating are the management costs and the common costs following expected inflation rate and the recovery of productivity. The updating of prices excludes capital costs, which contain depreciation provisioning, and the return on invested capital, including the planned investments. The intervention scenario we defined limits the annual growth of tariffs, as represented by equation 9 .

$$
\frac{T}{T_{t-1}} \leq(1+\mathrm{i}-\mathrm{X}+\mathrm{qlt}+\mathrm{biz})
$$

Therefore, tariffs evolve according to equation 10 .

$$
T=T_{t-1} * 1+[\mathrm{i}-\mathrm{X}+(0 \leq \mathrm{biz} \leq)+(0 \leq \mathrm{qlt} \leq 2)]
$$

Here, i represents the expected inflation, $0.1<X<0.5$ is the productivity recovery factor, biz is a factor that monitors the scope of service, and $q l t$ is a factor that defines the quality of the service. In this scenario, capital costs fall within the scope of the cost components that update in accordance with the price cap. In addition, the intervention scenario also considers the evolution of the WM disposal and collection service, both in terms of business model organization and quality of service.

This paper analyzes the simulation depicted in equation 11 for the evolution of costs, and consequently of waste tax, according to the price-cap in equation 10. This is done by means of sensitivity analysis. Hypothesis $1\left(\mathrm{H}_{1}\right)$ foresees no quality or business model 
improvements; hypothesis $2\left(\mathrm{H}_{2}\right)$ represents an intermediate hypothesis where both the business model optimization and quality of service parameters are set at their average level, that is, $(b i z=1.5 ; q l t=1)$. Finally, in hypothesis $3\left(\mathrm{H}_{3}\right)$, both variables are set at maximum levels. This can be formalized in equation 11 as follows:

$$
T=T_{t-1} * 1+ \begin{cases}0.7-0.3+0+0 & \text { if } H_{1} \\ 0.7-0.3+1.5+1 & \text { if } H_{2} \\ 0.7-0.3+3+2 & \text { if } H_{3}\end{cases}
$$

The three hypotheses embedded in equation 11 refer to a single period application of the price-cap mechanism in order to compare the hypothesized conditions with the intervention scenario. 


\section{Results}

WM costs can be split into different categories to reflect the typical activities that WM operators carry out, as depicted in Figure 2.

Figure 2: Costs by category

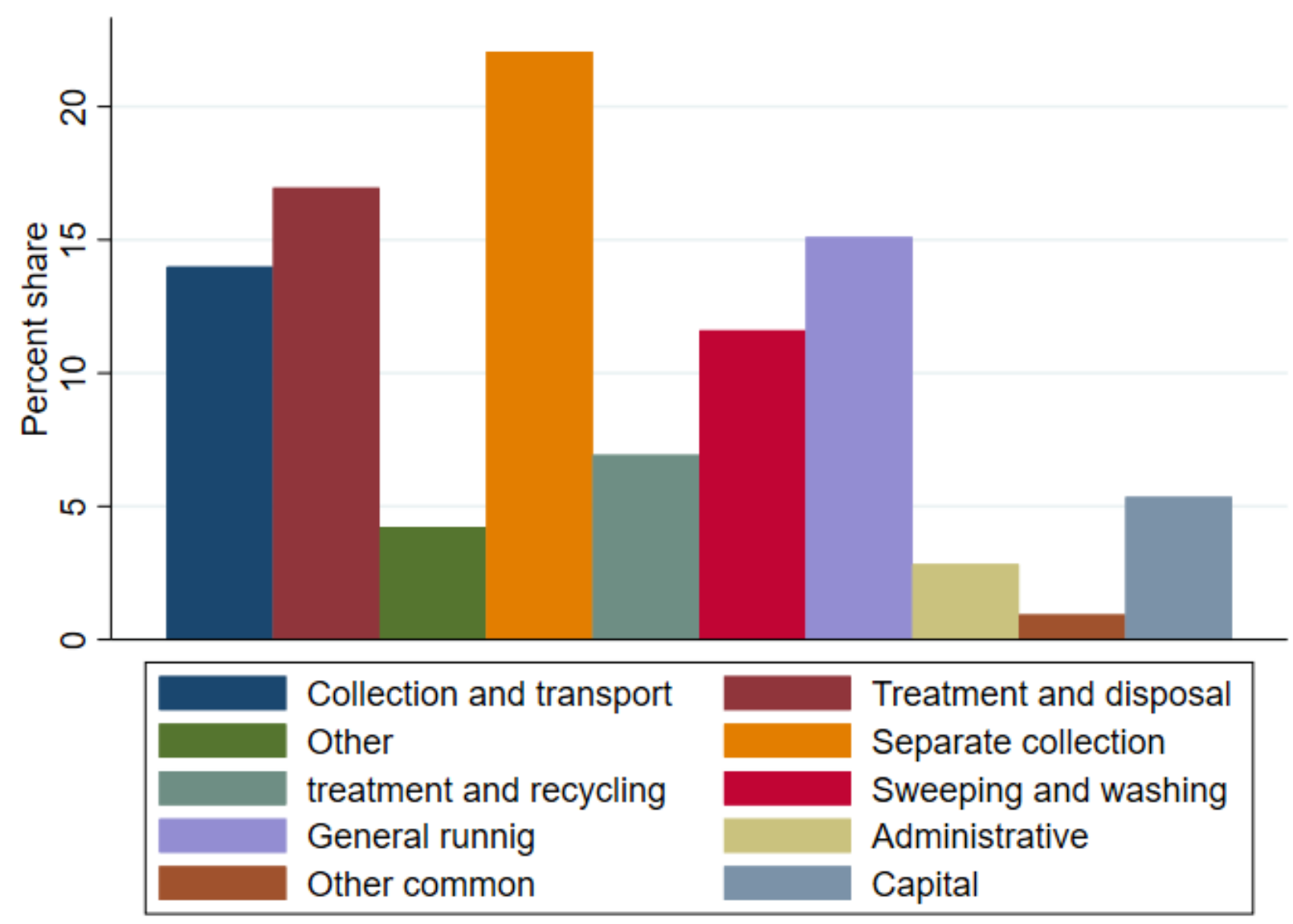

Figure 2 provides a synthesis of the structure of costs at a national level. Annex 1 contains a regional decomposition. Table 3 contains the estimations of variable and total costs according to equation 2 and equation 3. It can be seen here that both types of costs are lower in the intervention scenario than in the baseline.

\begin{tabular}{|c|c|c|c|c|}
\hline \multirow{2}{*}{ Territorial units } & \multicolumn{2}{|c|}{ Variable costs } & \multicolumn{2}{|c|}{ Fix costs } \\
\hline & $\begin{array}{c}\text { Baselin } \\
\mathrm{e}\end{array}$ & $\begin{array}{c}\text { Interventi } \\
\text { on }\end{array}$ & $\begin{array}{l}\text { Baselin } \\
\mathrm{e}\end{array}$ & $\begin{array}{c}\text { Interventi } \\
\text { on }\end{array}$ \\
\hline Abruzzo & 160.2 & 149.566 & 80.445 & 71.108 \\
\hline Aosta Valley & 15.711 & 15.306 & 6.948 & 7.147 \\
\hline Basilicata & 62.681 & 58.941 & 34.905 & 34.027 \\
\hline
\end{tabular}




\begin{tabular}{|c|c|c|c|c|}
\hline Calabria & $\begin{array}{c}206.28 \\
6\end{array}$ & 190.381 & 114.502 & 102.119 \\
\hline Campania & $\begin{array}{c}790.78 \\
6\end{array}$ & 731.81 & $\begin{array}{c}566.33 \\
8\end{array}$ & 519.522 \\
\hline Emilia R & 518.9 & 439.49 & $\begin{array}{c}250.58 \\
5\end{array}$ & 301.332 \\
\hline Friuli V G & 103.6 & 86.194 & 53.897 & 54.635 \\
\hline Lazio & $\begin{array}{c}821.48 \\
9\end{array}$ & 745.261 & 494.577 & 480.675 \\
\hline Liguria & 174.2 & 160.679 & 196.843 & 197.435 \\
\hline Lombardy & 799 & 661.265 & 660.1 & 663.423 \\
\hline Marche & 147.901 & 134.607 & 85.708 & 93.872 \\
\hline Molise & 26.524 & 25.492 & 16.993 & 14.234 \\
\hline Piedmont & 442.6 & 385.506 & $\begin{array}{c}266.00 \\
1\end{array}$ & $274 \cdot 328$ \\
\hline Apulia & 419.2 & 387.697 & $\begin{array}{c}368.53 \\
4\end{array}$ & 365.171 \\
\hline Sardinia & 183.1 & 163.218 & 170.507 & 156.078 \\
\hline Sicily & 587.517 & 549.294 & 279.351 & 250.469 \\
\hline Tuscany & $\begin{array}{c}398.98 \\
2\end{array}$ & 362.129 & 406.15 & 404.352 \\
\hline Trentino & 84.81 & 68.257 & 67.207 & 65.213 \\
\hline Umbria & 91.296 & 81.923 & 81.589 & 80.37 \\
\hline Veneto & 400.9 & 350.004 & $\begin{array}{c}254.50 \\
5\end{array}$ & 262.291 \\
\hline ITALY & $\begin{array}{c}6435.6 \\
83\end{array}$ & 5747.018 & $\begin{array}{c}4455.6 \\
84\end{array}$ & 4397.804 \\
\hline
\end{tabular}

Table 4 contains the estimate of management costs as in equation 4 , common costs as in equation 5 , and capital costs as in equation 6 . In Table 4 , the main noteworthy element is the fact that operating costs tend to decrease in the intervention scenario, while common costs and capital costs increase with some remarkable peaks.

\begin{tabular}{lllllll}
\hline \multicolumn{3}{c}{ Table4: Cost impact decomposition: management, common, and capital costs - EUR (millions) } \\
\hline Territorial units & \multicolumn{2}{c}{ Management costs } & \multicolumn{2}{c}{ Common costs } & \multicolumn{3}{c}{ Capital costs } \\
Abruzzo & 199.1 & 183.6 & 30.745 & 31.874 & 10.8 & 14.93 \\
Aosta Valley & 19.428 & 19.066 & 2.516 & 2.627 & 0.714 & 1.077 \\
Basilicata & 77.238 & 73.881 & 15.011 & 15.452 & 5.337 & 7.022 \\
Calabria & 258.119 & 239.413 & 53.053 & 54.429 & 9.616 & 13.462 \\
Campania & 1017.991 & 953.417 & 276.436 & 282.167 & 62.697 & 70.139 \\
Emilia R & 633.6 & 614.2 & 109.785 & 113.564 & 26.1 & 89.445 \\
Friuli V G & 129.879 & 120.4 & 22.243 & 23.001 & 5.374 & 14.229 \\
Lazio & 1035.803 & 1003.229 & 201.287 & 207.511 & 78.975 & 86.444 \\
Liguria & 224.6 & 213.9 & 120.843 & 122.63 & 25.6 & 33.675 \\
Lombardy & 1073.2 & 1006 & 316.2 & 323.13 & 69.7 & 127.75 \\
Marche & 185.249 & 176.017 & 34.427 & 35.626 & 13.934 & 29.171
\end{tabular}




\begin{tabular}{lllllll} 
Molise & 34.91 & 31.307 & 7.477 & 7.67 & 1.13 & 1.629 \\
Piedmont & 542.3 & 516.1 & 132.401 & 135.777 & 33.9 & 62.35 \\
Apulia & 552.3 & 528.2 & 191.134 & 194.794 & 44.3 & 58.45 \\
Sardinia & 241.7 & 222 & 80.107 & 81.688 & 31.8 & 34.225 \\
Sicily & 757.258 & 711.085 & 84.472 & 88.796 & 25.137 & 34.645 \\
Tuscany & 496.192 & 467.482 & 212.139 & 216.108 & 96.8 & 116.57 \\
Trentino & 110.373 & 102.371 & 30.019 & 30.726 & 11.624 & 16.361 \\
Umbria & 110.737 & 106.896 & 53.129 & 53.945 & 9.019 & 10.172 \\
Veneto & 487.9 & 468.8 & 127.605 & 131.042 & 39.9 & 60.6 \\
ITALY & 8187.878 & 7757.363 & 2101.03 & 2152.556 & 602.459 & 882.348 \\
\hline
\end{tabular}

Source: own elaboration

Figure 3 shows the potential impact of regulation on the total cost of providing the solid waste collection and disposal service. Specifically, it shows that the management costs in the intervention scenario will be approximately $94.44 \%$ of the baseline scenario management costs and common costs will be approximately equivalent $(+2.80 \%)$. By contrast, it is interesting to see that the CK are strongly influenced by the policy change, such that they increase by $57.20 \%$. Accordingly, variable costs in the intervention scenario decrease by $9.90 \%$, while fix costs decrease by $1.70 \%$.

Figure 3: Total costs in intervention scenario - change from baseline 

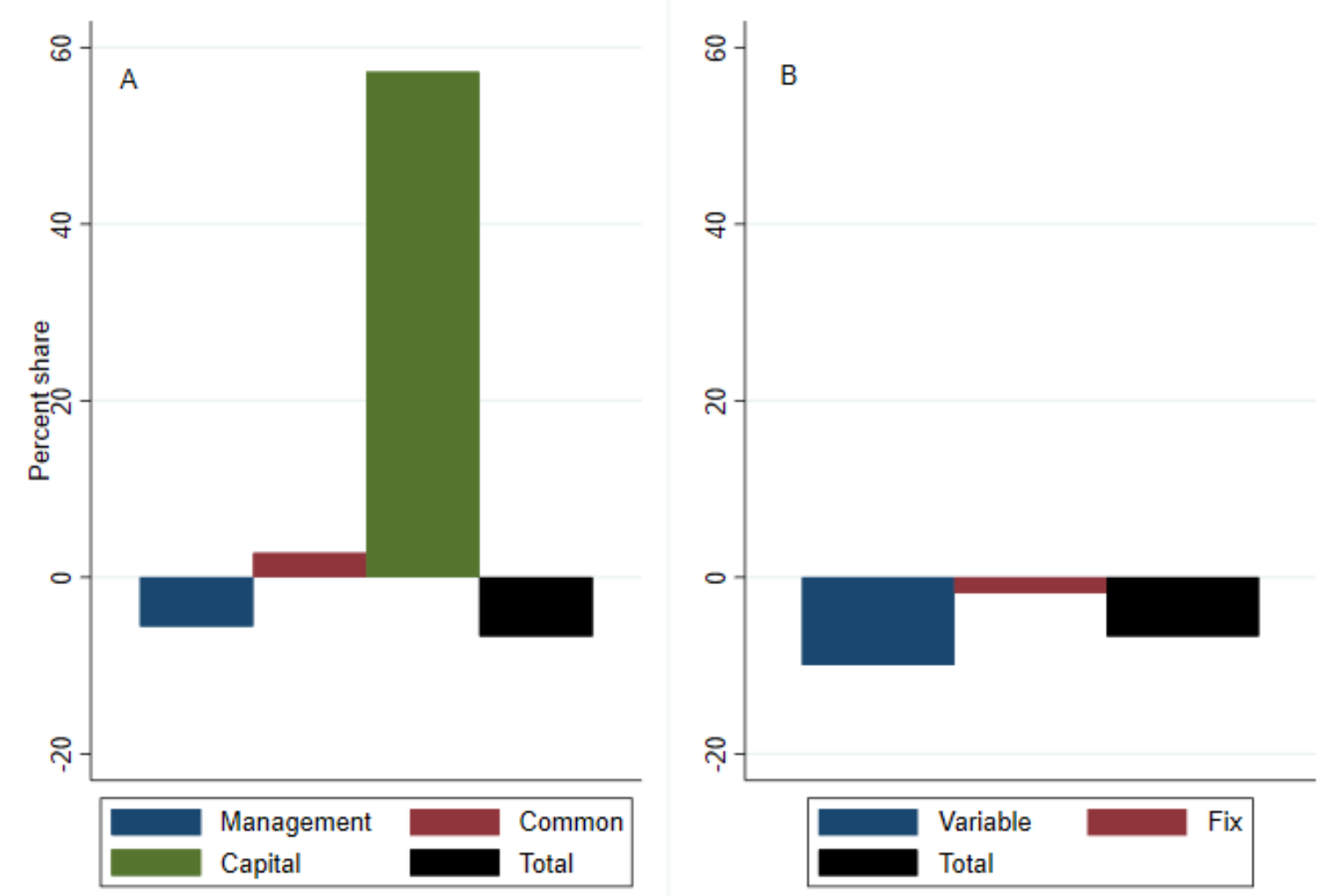

Percent change of costs structure: $\mathrm{A}: \mathrm{TC}=\mathrm{MC}+\mathrm{CC}+\mathrm{CK} \mid \mathrm{B}: \mathrm{TC}=\mathrm{TV}+\mathrm{TF}$

Source: Own elaboration

Figure 4 highlights the impact of the policy on total costs. It emphasizes the ratio of the predicted total cost of production to the actual data at the regional level.

Figure 4: Total costs in baseline and intervention scenario 


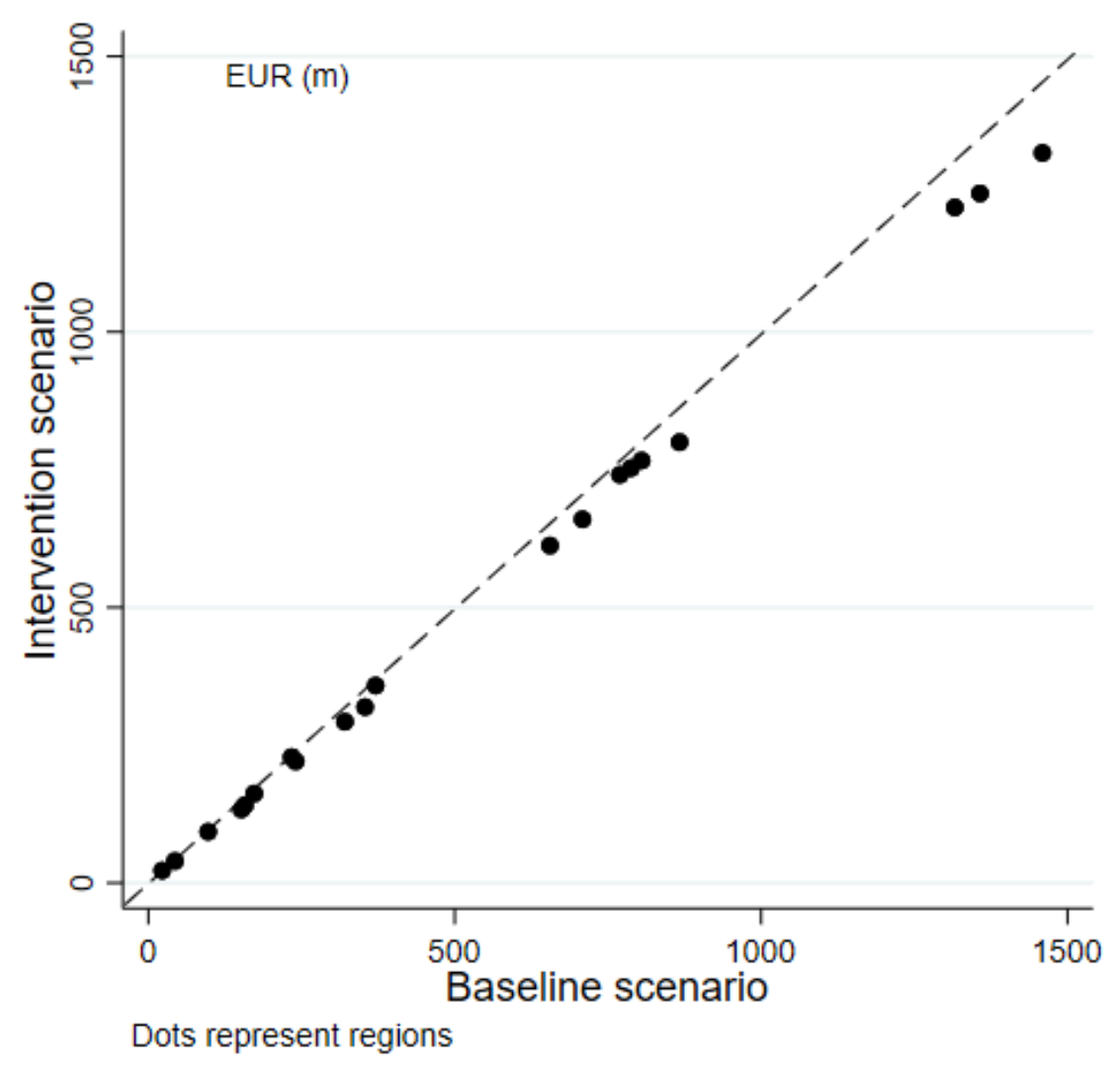

Source: Own elaboration

The interesting point is that, in the smaller regions, the variation between the baseline and intervention scenarios is not significant. The significance of the gain-sharing plan increases relative to the size of a region. This should be considered in conjunction with the evidence that showed that the most populated regions also show higher percentages of separated waste collection. That said, this relationship can be explained by equation 3 , which contains the variables $b\left(r_{m e}\right)$ and $r_{p a c k}$. These variables are decisive in explaining this outcome. In fact, revenues from the sale of materials and energy and which are accrued based on the proposed tariff system correspond to social surplus in the form of a cost reduction. Factor $b$, therefore, represents a positive externality related to the performance of the separate collection of different waste types. Revenues from the national packaging consortium are affected in a similar way. At the national level, the intervention scenario involves a reduction in the financial requirement for WM of 746 million euros which, compared to the current financial requirement of 10.8 billion euros, corresponds to a saving of $6.90 \%$. To further verify this 
result, sensitivity analysis based on predictions according to the previously described model can be conducted. Table 5 introduces a dynamic perspective in order to appraise the potential impact of the incentive regulation based on the sensitivity analysis.

\begin{tabular}{lccc}
\hline Table 5: Sensitivity analysis & & & \\
\hline Scenario & Hypotheses & Total EUR (millions) & Delta EUR (millions) \\
\hline Intervention & - & 10144.8 & \\
A: $b i z=0 ;$ qlt $=0$ & $\mathrm{H} 1$ & 10185.4 & 40.6 \\
B: $b i z=1 ; q l t=1$ & $\mathrm{H} 2$ & 10439.0 & 294.2 \\
C: $b i z=3 ; q l t=2$ & $\mathrm{H} 3$ & 10692.6 & 547.8 \\
\hline
\end{tabular}

Source: own elaboration

With respect to service quality improvements, which are captured in the different levels of $q l t$, it is considered that the changes in the service may include better forecasts regarding increases in the percentage of separate collection, as well as improvement in the services provided.

\section{Discussion}

Our analysis is based on a simulation that allowed us to compare the baseline scenario with an intervention scenario, which could generate positive externalities for society, given that scholars are calling for expanded use of market-based instruments in WM (Beccarello and Di Foggia, 2016; Farley et al., 2015). Based on the simulations, it was possible to estimate positive externalities for society. That is, the benefit of sharing revenues from the sale of materials and energy and from the national packaging consortium was estimated. These positive externalities amounted to 746 million euros per year, which is $6.9 \%$ of the current funding requirement for WM in Italy. In addition, as hypothesized, our results showed that the application of incentive regulation may lead to variations in the total costs, and therefore in the fees charged to users, which could lead to a surplus of 5.4\% for WM companies, assuming $0.7 \%$ expected inflation and factor $\mathrm{X}$ being set to $0.3 \%$.

This result has policy significance. It means that the scope of the price-cap formula, that is, the recognized cost is defined, may weaken economic returns to the point of the surplus being counterbalanced by the cost. Given that the application of incentive regulation is based on previous periods, this could penalize efficient regions by increasing their environmental targets and reducing coverage of their funding requirements, while less efficient regions would be rewarded with complete economic coverage. Consequently, it 
would be appropriate to take the initial conditions of the efficiency of the different regions into account. Overall, the implications of this research may help to define strategies for creating the conditions for developing favorable regulations for WM, while considering that the evolution of the regulatory environment can be costly.

New regulations can be expensive in terms of compliance as companies need to transform data tracking and gathering systems, reporting functions and, in some cases, their organizational structures (Cagno et al., 2018). Therefore, these results are useful for scholars and policy makers so that they can define regulations for the financing of the WM sector in a way which considers key elements of efficiency. This will contribute to achieving the objectives set by the European directive on the circular economy The signaling function of cost-reflective tariffs on an allocation level must include a fee paid by the user that correctly reflects the cost he/she generated. This means that a user generates costs when he/she produces waste but produces benefits when he/she adopts virtuous behavior.

The current Italian tariff system foresees the division of costs into fixed costs and variable costs. On an economic level, the service provision under a legal monopoly is justified by the need to avoid duplication of costs and to correctly allocate fixed and variable costs to users through the fixed and variable components of the two-part tariff. Thus, regulation must consider the correspondence between fixed and variable parts of tariffs and production costs. With this in mind, it is fundamental to a tariff structure to be able to provide signals to users and encourage virtuous behavior. In this way, tariffs can be a tool that can be used to improve the quality of WM. This would help to achieve environmental objectives and to reconcile them with the containment of tariffs.. The introduction of environmental parameters in the tariffs can incentivize users to undertake virtuous behavior, which is useful for the achievement of environmental objectives. The development of tariffs that recognize and reward the virtuous behavior of the user has several advantages, e.g. the effective dissemination of information to the users, and the overall increase in system performance. Finally, it is necessary to deepen this line of research with new studies to strengthen the coherence and the correct allocation of incentives within tariffs.

\section{Conclusion}

The motivation for this research is the need to understand how gain-sharing, cost-reflective tariffs can encourage WM operators and users to respond to environmental policies. Since 
incentive regulatory frameworks often imply higher complexity (Elia et al., 2015) and a greater amount of resources needed to manage the service (Morlok et al., 2017), this paper has given an account of the potential benefits to society. The distribution of benefits to society can occur through the sharing of materials and energy revenue with taxpayers according to their response to policies, such as reducing their waste production and increasing their performance of separating different waste types. Thus, a stimulus for the reduction of waste and the separate collection and recovery of waste streams is generated by ensuring that a share of the revenues accrues to the users.

We have argued that the introduction of a gain-sharing cost-reflective tariff, which is implemented by applying variable rates and subsidizing users according to their environmental performance, may produce positive externalities that increase social surplus. Our results demonstrate that the surplus would add up to $6.9 \%$ of the current total WM funding requirement in Italy. This goal can be achieved by designing sound regulation with cost-reflective tariff schemes to incentivize users' behavior. In addition, we have argued that it is necessary to design asymmetric regulation in order to consider differences in environmental performance and economic efficiency in different territories. If this is not done, a paradoxical outcome could emerge, which would be detrimental to efficient WM. Given that the incentive regulation is based on previous periods, this could penalize regions with higher environmental and economic performance, while inefficient regions would be rewarded with increased provision of funding. This paradox is explained by the role of revenues from the sale of materials and energy and the revenues from the national packaging consortium. In fact, these revenues explain most of the positive externalities that would benefit the population. Since both variables depend on the performance of separated waste collection, less-virtuous regions, that is, regions where waste separation is poorly performed, may be subject to lower variations due to intervention. In addition, in order for the surplus to be generated, policy makers must define the scope of the price-cap mechanism.

To examine this issue, sensitivity analysis based on three hypotheses was conducted. In hypothesis 1, no quality or business model improvements were expected. Hypothesis 2 represented an intermediate hypothesis where both business model optimization and quality of service factors were set at their average level, and finally, in hypothesis 3, both factors were set to their maximum. The latter scenario showed a 5.4\% increase in allowed revenues for WM companies and an equivalent economic surplus. However, incentive 
regulation based on a price-cap mechanism on maximum allowed revenues could undermine this surplus. Indeed, the price-cap level may prompt an increase in the tariff that would counterbalance the surplus that emerged from good users' behavior if poor users' behavior is rewarded in the fee-rebate structure. Thus, policy makers must not only consider that incentive regulation must reflect users' behavior at the time of the introduction of the regulation. Regulations must also strategically enable benefits to accrue appropriately throughout subsequent periods.

\section{REFERENCES}

Beccarello, M., Di Foggia, G., 2016. Economic Analysis of EU Strengthened Packaging Waste Recycling Targets. J. Adv. Res. Law Econ. 7, 1930-1941. https://doi.org/10.14505/jarle.v7.8(22).02

Bel, G., Fageda, X., 2010. Empirical analysis of solid management waste costs: Some evidence from Galicia, Spain. Resour. Conserv. Recycl. 54, 187-193. https://doi.org/10.1016/J.RESCONREC.2009.07.015

Bohm, R.A., Folz, D.H., Kinnaman, T.C., Podolsky, M.J., 2010. The costs of municipal waste and recycling programs. Resour. Conserv. Recycl. 54, 864-871. https://doi.org/10.1016/j.resconrec.2010.01.005

Brown, T., Faruqui, A., Grausz, L., 2015. Efficient tariff structures for distribution network services. Econ. Anal. Policy 48, 139-149. https://doi.org/10.1016/J.EAP.2015.11.010

Buclet, N., Godard, O., 2001. The evolution of municipal waste management in Europe: how different are national regimes? J. Environ. Policy Plan. 3, 303-317. https://doi.org/10.1002/jepp.91

Cagno, E., Micheli, G.J.L., Di Foggia, G., 2018. Smart metering projects: an interpretive framework for successful implementation. Int. J. Energy Sect. Manag. 12, 244-264. https://doi.org/10.1108/IJESM-08-2017-0009

Chamizo-González, J., Cano-Montero, E.-I., Muñoz-Colomina, C.-I., 2018. Does funding of waste services follow the polluter pays principle? The case of Spain. J. Clean. Prod. 183, 1054-1063. https://doi.org/10.1016/J.JCLEPRO.2018.02.225

Chu, L.Y., Sappington, D.E.M., 2012. Designing optimal gain sharing plans to promote energy conservation. J. Regul. Econ. 42, 115-134. https://doi.org/10.1007/s11149-012-9194-3

Chu, Z., Wang, W., Zhou, A., Huang, W.-C., 2019. Charging for municipal solid waste disposal in Beijing. Waste Manag. 94, 85-94. https://doi.org/10.1016/J.WASMAN.2019.05.051

Cooremans, C., 2011. Make it strategic! Financial investment logic is not enough. Energy Effic. 4, 473-492. https://doi.org/10.1007/s12053-011-9125-7

D’Onza, G., Greco, G., Allegrini, M., 2016. Full cost accounting in the analysis of separated waste collection efficiency: A methodological proposal. J. Environ. Manage. 167, 59-65. 
https://doi.org/10.1016/J.JENVMAN.2015.09.002

Debnath, S., Bose, S.K., 2014. Exploring full cost accounting approach to evaluate cost of MSW services in India. Resour. Conserv. Recycl. 83, 87-95. https://doi.org/10.1016/J.RESCONREC.2013.12.007

Di Foggia, G., 2018. Energy efficiency measures in buildings for achieving sustainable development goals. Heliyon 4, eo0953. https://doi.org/10.1016/j.heliyon.2018.e00953

Di Foggia, G., Beccarello, M., 2018. Improving efficiency in the MSW collection and disposal service combining price cap and yardstick regulation: The Italian case. Waste Manag. 79, 223-231. https://doi.org/10.1016/j.wasman.2018.07.040

Di Foggia, G., Lazzarotti, V., 2014. Assessing the link between revenue management and performance: insights from the Italian tourism industry. Meas. Bus. Excell. 18, 55-65. https://doi.org/10.1108/MBE-11-2013-0059

EEA, 2016. Municipal waste management across European countries See. https://doi.org/10.280o/475915

Elia, V., Gnoni, M.G., Tornese, F., 2015. Designing Pay-As-You-Throw schemes in municipal waste management services: A holistic approach. Waste Manag. 44, 188-195. https://doi.org/10.1016/J.WASMAN.2015.07.040

Farley, J., Schmitt Filho, A., Burke, M., Farr, M., 2015. Extending market allocation to ecosystem services: Moral and practical implications on a full and unequal planet. Ecol. Econ. 117, 244252. https://doi.org/10.1016/j.ecolecon.2014.06.021

Fuss, M., Vasconcelos Barros, R.T., Poganietz, W.-R., 2018. Designing a framework for municipal solid waste management towards sustainability in emerging economy countries - An application to a case study in Belo Horizonte (Brazil). J. Clean. Prod. 178, 655-664. https://doi.org/10.1016/J.JCLEPRO.2018.01.051

Goddard, H.C., 1995. The benefits and costs of alternative solid waste management policies. Resour. Conserv. Recycl. 13, 183-213. https://doi.org/10.1016/o921-3449(94)0o021-V

Guerriero, C., 2013. The political economy of incentive regulation: Theory and evidence from US states. J. Comp. Econ. 41, 91-107. https://doi.org/10.1016/J.JCE.2012.05.003

Gullì, L., Zazzi, M., 2011. Renewal strategies for the environmental conversion of crafts districts in Italy. Procedia Eng. 21, 771-779. https://doi.org/10.1016/j.proeng.2011.11.2077

Hoornweg, D., Bhada-Tata, P., 2012. What a waste. A Global Review of Solid Waste Management (No. 15), Urban Development knowledge. Washington.

Jargstorf, J., De Jonghe, C., Belmans, R., 2015. Assessing the reflectivity of residential grid tariffs for a user reaction through photovoltaics and battery storage. Sustain. Energy, Grids Networks 1, 85-98. https://doi.org/10.1016/J.SEGAN.2015.01.003

Kirchherr, J., Reike, D., Hekkert, M., 2017. Conceptualizing the circular economy: An analysis of 114 definitions. Resour. Conserv. Recycl. 127, 221-232. https://doi.org/10.1016/j.resconrec.2017.09.005

Kitching, J., Hart, M., Wilson, N., 2015. Burden or benefit? Regulation as a dynamic influence on small business performance. Int. Small Bus. J. Res. Entrep. 33, 130-147. 
https://doi.org/10.1177/0266242613493454

Lakhan, C., 2016. The relationship between municipal waste diversion incentivization and recycling system performance. Resour. Conserv. Recycl. 106, 68-77.

https://doi.org/10.1016/j.resconrec.2015.11.010

Lavee, D., Khatib, M., 2010. Benchmarking in municipal solid waste recycling. Waste Manag. 30, 2204-2208. https://doi.org/10.1016/J.WASMAN.2010.03.032

Lavee, D., Nardiya, S., 2013. A cost evaluation method for transferring municipalities to solid waste source-separated system. Waste Manag. 33, 1064-1072. https://doi.org/10.1016/J.WASMAN.2013.01.026

Mani, S., Singh, S., 2016. Sustainable Municipal Solid Waste Management in India: A Policy Agenda. Procedia Environ. Sci. 35, 150-157. https://doi.org/10.1016/J.PROENV.2016.07.064

Marques, R.C., Simões, P., Pinto, F.S., 2018. Tariff regulation in the waste sector: An unavoidable future. Waste Manag. 78, 292-300. https://doi.org/10.1016/J.WASMAN.2018.05.028

Morlok, J., Schoenberger, H., Styles, D., Galvez-Martos, J.L., Zeschmar-Lahl, B., 2017. The impact of pay-as-you-throw schemes on municipal solid waste management: The exemplar case of the county of Aschaffenburg, Germany. Resources 6. https://doi.org/10.3390/resources6010008

Nelles, M., Grünes, J., Morscheck, G., 2016. Waste Management in Germany - Development to a Sustainable Circular Economy? Procedia Environ. Sci. 35, 6-14. https://doi.org/10.1016/J.PROENV.2016.07.001

Pérez-Arriaga, I.J. (Ed.), 2014. Regulation of the power sector. Springer Science \& Business Media, London. https://doi.org/10.1007/978-1-4471-5034-3

Pérez-López, G., Prior, D., Zafra-Gómez, J.L., Plata-Díaz, A.M., 2016. Cost efficiency in municipal solid waste service delivery. Alternative management forms in relation to local population size. Eur. J. Oper. Res. 255, 583-592. https://doi.org/10.1016/j.ejor.2016.05.034

Pirard, R., Lapeyre, R., 2014. Classifying market-based instruments for ecosystem services: A guide to the literature jungle. Ecosyst. Serv. 9, 106-114.

https://doi.org/10.1016/j.ecoser.2014.06.005

Sarra, A., Mazzocchitti, M., Rapposelli, A., 2017. Evaluating joint environmental and cost performance in municipal waste management systems through data envelopment analysis: Scale effects and policy implications. Ecol. Indic. 73. https://doi.org/10.1016/j.ecolind.2016.10.035

Shleifer, A., 1985. A Theory of Yardstick Competition. RAND J. Econ. 16, 319-237.

Simões, P., Marques, R.C., 2012a. On the economic performance of the waste sector. A literature review. J. Environ. Manage. 106, 40-47. https://doi.org/10.1016/j.jenvman.2012.04.005

Simões, P., Marques, R.C., 2012b. Influence of regulation on the productivity of waste utilities. What can we learn with the Portuguese experience? Waste Manag. 32, 1266-1275. https://doi.org/10.1016/J.WASMAN.2012.02.004

Swart, J., Groot, L., 2015. Waste management alternatives: (Dis)economies of scale in recovery and decoupling. Resour. Conserv. Recycl. 94, 43-55. https://doi.org/10.1016/J.RESCONREC.2014.11.005 
Tisserant, A., Pauliuk, S., Merciai, S., Schmidt, J., Fry, J., Wood, R., Tukker, A., 2017. Solid Waste and the Circular Economy: A Global Analysis of Waste Treatment and Waste Footprints. J. Ind. Ecol. 21, 628-640. https://doi.org/10.1111/jiec.12562

Tsilemou, K., Panagiotakopoulos, D., 2006. Approximate cost functions for solid waste treatment facilities. Waste Manag. Res. 24, 310-322. https://doi.org/10.1177/0734242Xo6066343

UNEP, 2012. Sustainable, Resource Efficient Cities - Making It Happen. United Nations Environment.

van Beukering, P., Kuik, O., Oosterhuis, F., 2014. The Economics of Recycling, in: Worrell, E., Reuter, M. (Eds.), Handbook of Recycling. State-of-the-Art for Practitioners, Analysts, and Scientists. Elsevier Inc, pp. 479-489. https://doi.org/doi:10.1016/B978-0-12-3964595.00031-3

World Bank, 2018. Municipal solid waste management. A roadmap for reform for policy makers.

\section{ANNEXES}

Annex 1: Decomposition of production costs at a regional level

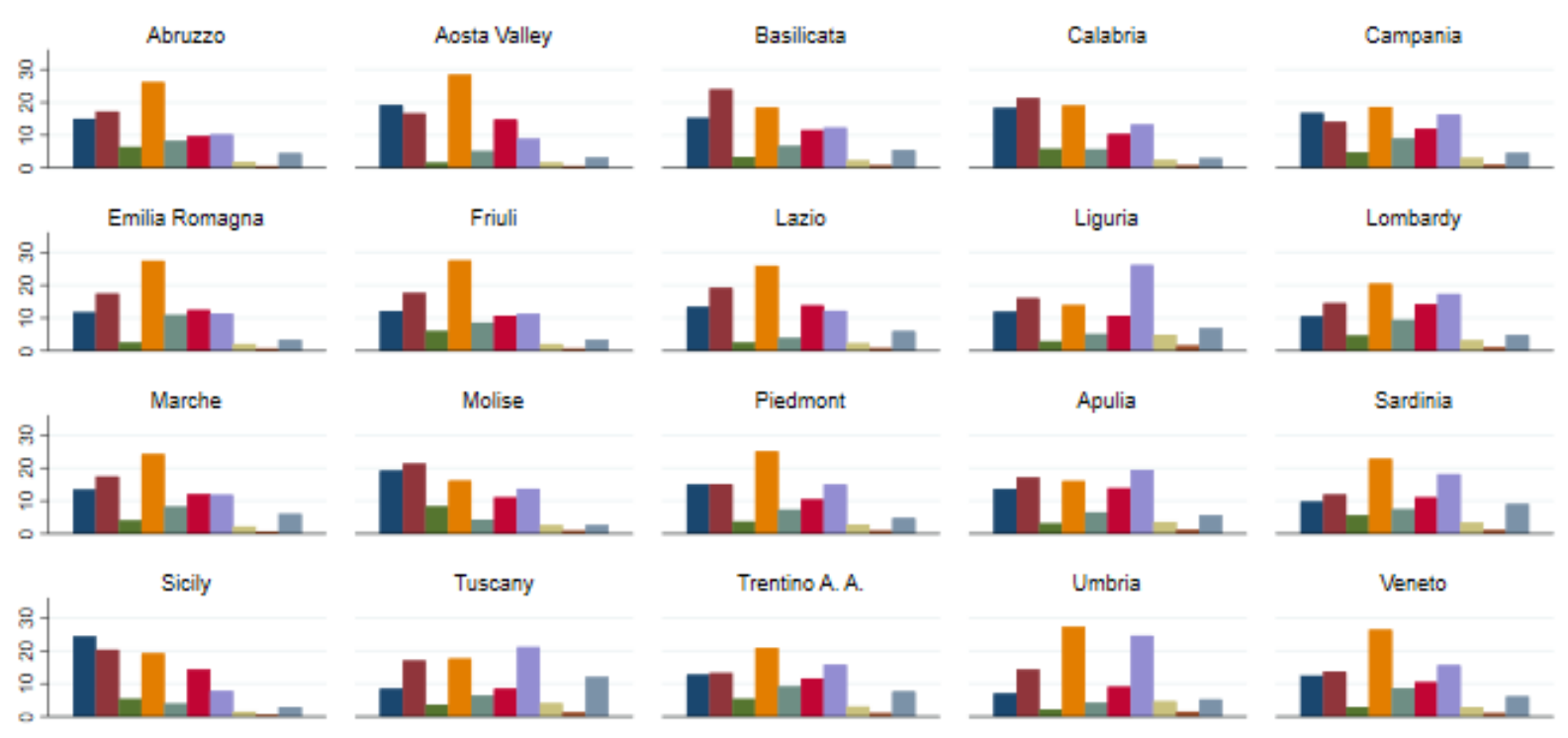

\begin{tabular}{|l|l|}
\hline Collection and transport & Treatment and disposal \\
\hline Other & Separate colletion \\
Treatment and recycling & Sweeping and washing \\
General runnig & Administrative \\
\hline Other common & Capital \\
\hline
\end{tabular}

Graphs by Region 
